\title{
ORÍGENES DE LA MISIÓN MILAGRO
}

\author{
GARCÍA-ALCOLEA EE ${ }^{1}$
}

En Cuba han existido numerosas muestras de solidaridad hacia otros países, gracias al legado del pensamiento latinoamericanista de José Martí y Ernesto Che Guevara y la continuidad de estas ideas por el Comandante en Jefe Fidel Castro Ruz. Esta solidaridad no sólo se ha evidenciado en el campo de la salud, sino también en temas de construcción, agricultura, azúcar, educación, transporte, comunicación y desarrollo de otras industrias.

Sin contar aún con una consolidación económica y política, dados los pocos años de surgida la Revolución, Cuba comenzó a brindar su ayuda, a pesar de la salida masiva al extranjero de médicos que se produjo a partir de 1959, cuando sólo contábamos con 6.286 médicos y emigró la mitad de esta cifra, incluyendo un tercio de los profesores de la única escuela de medicina que había en Cuba.

El primer indicio de colaboración se reconoce en 1960, cuando se envió a Chile una brigada médica emergente y varias toneladas de equipos de insumo, después de haber pasado este país por un intenso terremoto que dejó miles de fallecidos.

No obstante, se reconoce el 23 de Mayo de 1963 como el inicio de la Colaboración Médica Internacional Cubana de brigadas permanentes, en esta ocasión con una brigada de 55 colaboradores que prestarían sus servicios durante un año en Argelia. De esta manera se manifiesta la desinteresada solidaridad de Cuba para ayudar a otros países que necesitan de nuestros servicios, sin intereses comerciales ni diplomáticos.

En los 50 años de historia de colaboración médica se ha multiplicado el número de colaboradores y de países en los cuales se presta servicios, se han alcanzado mayores categorías científicas y docentes en los colaboradores enviados a estas misiones y se gana en experiencia para trabajar en base a mejorar la calidad de la asistencia médica. También se han abierto un significativo número de universidades médicas en el extranjero y de igual forma ha aumentado el número de estudiantes extranjeros que estudian las carreras de Medicina, Estomatología, Licenciatura en Enfermería y Técnicos de la Salud, graduándose hasta el momento 8.449 de 100 países diferentes (1).

Por otro lado, durante las consultas realizadas a las comunidades en los sitios más recónditos de cada barrio, con la aparición del programa solidario Barrio Adentro en el año 2003 en la República Bolivariana de Venezuela, los médicos cubanos comenzaron a descubrir enfermedades, como cataratas y pterigion no tratadas, según los afectados por falta de dinero para ir al hospital o a la clínica privada o porque en los hospitales el tratamiento o la intervención nunca se producía. Con el propósito de brindarle a la población la oportunidad de mirar el mundo con mayor nitidez y mayor claridad nace la Misión Milagro, arcoiris de esperanza. Es considerada como la hermana destacada de Barrio Adentro que llegó a Venezuela de la mano de una delegación cubana para llenar de luz los ojos de miles de personas que ya habían perdido la ilusión de volver a ver (2).

La Misión Milagro, iniciativa de Cuba apoyada por Venezuela, es una campaña de contenido social y humanitario que no distingue condición social, edad, ni raza de los pacientes. Las operaciones que se realizan en su contexto, sin costo alguno, permiten devolver la visión o curar de diversos padecimientos oftalmológicos a ciudadanos de países del llamado tercer mundo. Desde el 10 de julio de 2004, en que se realizaron las primeras 50 intervenciones, Cuba impulsó ese proyecto para preservar y devolver la visión en 10 años a no menos de seis millones de enfermos latinoamericanos y caribeños sin recursos económicos, lo que se conoce como Convenio de Sandino. Médicos y técnicos cubanos, con el apoyo de equipos y la tecnología oftalmológica más avanzada, crean capacidades para operar anualmente a cerca de un millón de pacientes, en el contexto de la Alternativa Bolivariana para los Pueblos de nuestra América (ALBA). De acuerdo con estadísticas de

\footnotetext{
${ }^{1}$ Doctor en Medicina. Oftalmología y Medicina General Integral. Facultad Cubana de Oftalmología. La Habana. Cuba. E-mail: egarciaalcolea@yahoo.com
} 
organismos internacionales, alrededor de 50 millones de personas son ciegas en el mundo, un millón y medio de ellas menores de 16 años. La Organización Mundial de la Salud (OMS) informó recientemente que en América Latina unos cinco millones de niños, jóvenes y adultos necesitan operaciones oftalmológicas diversas, mientras en el Caribe la cifra se eleva a medio millón: de ahí la gran importancia de este proyecto humanitario $(2,3)$.

Los primeros pasos de la Misión Milagro se producen por la falta de respuestas inmediatas ante los casos de parasitismo, diarrea, problemas respiratorios, hipertensión y diabetes, lo que condujo al alcalde Freddy Bernal a proponerle al Presidente Hugo Chávez que solicitara colaboración a la República de Cuba para dar respuestas a las comunidades (2). Cuba y Venezuela con el proyecto «Misión Milagro», brindan salud y bienestar a los Latinoamericanos y del Caribe. Con este trabajo se han beneficiado hasta la fecha más de un millón de latinoamericanos; además ha sido aceptada por los sectores más pobres de nuestro continente, ya que le ha devuelto la visión de forma gratuita a muchos de sus habitantes que ya habían perdido las esperanzas de recuperarla y vivían en la oscuridad, con un mínimo de complicaciones, empleándose las técni- cas más avanzadas en el mundo y por un personal altamente calificado. Esta misión no sólo ha hecho posible la relación entre sociedades y gobiernos, sino también entre la cultura de varios países. La consolidación de una nueva cultura científico-tecnológica que se corresponda con las exigencias y demandas de esta realidad, es una necesidad, ya que Ciencia y Tecnología no son neutros, subyacen en el contexto sociopolítico que los ha generado y que este aspecto hoy enfocando a las afecciones visuales, donde la Ceguera y Baja Visión en el mundo, constituyen fundamentalmente un problema social, son a su vez el objetivo más importante de la Misión Milagro (4).

\section{BIBLIOGRAFÍA}

1. Márquez M, Rojas Ochoa F, Gutiérrez Muñiz JA, López Pardo C. Salud para todos Si es posible. 1. ${ }^{a}$ ed. La Habana: Sociedad Cubana de Salud Pública. Sección de Medicina Social 2005; 42-283.

2. Misión Milagro: Mirando Hacia el Horizonte desde Barrio Adentro. Caracas, septiembre 2006. Ministerio de Salud y Desarrollo Social.

3. Misión Milagro: Convenio Solidario. Octubre 2005. Disponible en: www.minci.gob.ve

4. Misión Milagro. Disponible en: www.msds.gov.ve 